\title{
Hypoplastic Left Heart Syndrome -A Rare Case Report
}

\author{
Dhananjay.Y.Shrikhande ${ }^{1}$, Rajib Chatterjee ${ }^{2}$, NileshManiya ${ }^{3}$, Divyank Pathak ${ }^{4}$, \\ Anuj Kumar ${ }^{5}$ \\ ${ }^{1}$ Professor and Head of Department, Department of Pediatrics,,Rural Medical College, Pravara Institute of \\ Medical Sciences, Loni, India \\ ${ }^{2}$ Professor, Department of Pediatrics, Rural Medical College, Pravara Institute of Medical Sciences, Loni, \\ India \\ ${ }^{3,4,5}$ Post graduate student, Department of Pediatrics,,Rural Medical College, Pravara Institute of Medical \\ Sciences, Loni, India
}

\begin{abstract}
The term Hypoplastic left heart is used to describe a related group of anomalies that include under development of the left side of the heart (atresia of the aortic or mitral orifice) and hypoplasia of the ascending aorta. the left ventricle may be moderately hypolastic, very small and non functional, or totally atretic, in the immediate neonatal period. The right ventricle maintain the both upper pulmonary circulation and the systemic circulation via the ductusarteriosus. Hypoplastic left heart syndrome (HLHS) has been reported to occur in approximately 0.016 to $0.036 \%$ of all live births. Here we present a rare case report- Hypoplastic left heart Syndrome.
\end{abstract}

Keywords: Hypoplastic left heart syndrome, Hypoplastic arch, HypoplasticLV ,Single-ventricle, Norwood procedure, Sano procedure

\section{Introduction}

Hypoplastic left heart syndrome(HLHS) refers to the abnormal development of the left-sided cardiac structures, resulting in obstruction to blood flow from the left ventricular outflow tract ${ }^{1}$. In addition, the syndrome includes underdevelopment of the left ventricle, aorta, and aortic arch, as well as mitral atresia or stenosis.TheHypoplastic left heart syndrome may be a progressive lesion, beginning with simple valvar aortic stenosis in mid gestation period. The decrease flow through the stenotic aortic valve reduce the flow throught the left ventricle during development, resulting in gradual ventricular chamber hypoplasia ${ }^{2}$. .HLHS is potentially detectable on prenatal sonography between 18 and 22 weeks' gestation with a 4-chamber view of the fetal heart and it is one of the most common cardiac malformation detected in fetal life ${ }^{3}$.

\section{Case Report}

Baby boy delivered normally at term weighing $2530 \mathrm{gms}$, length $49 \mathrm{cms}$, presented on $3^{\text {rd }}$ day of life with respiratory distress. OnExamination there was central cyanosis and pallor with cold extremities ,weak peripheral pulses, poor perfusion in shock. Auscultation revealed loud S2 . Due to progressive deterioration, mechanical ventilation was provided with inotropic support. However, baby could not be revived .On Ultrasonography 29 weeks single, live intrauterine pregnancy with dilated fetal aorta. Fetal echocardiography showed heart more in left hemithorax, two chambered heart -morphological RA and RV . LA severelyhypoplastic to atretic and LV atretic. Large RA and large RV, single pulmonary vein draining into almost atreticLA . Large pulmonary trunk arising from the RV, dividing into RPA and LPA ; ductus arch large and continuing into descending thoracic aorta. Ascending aortic -atretic.Postnatal echocardiography done on 1 day of life which revealed Mitral atresia, aortic atresia, Rudimentary and Hypoplastic LV. Small , restrictive PFO measuring $3.2 \mathrm{~mm}$, left to right shunt with severe PH, Hypoplastic arch, Pulmonary artery largely continuing as descending aorta - HLHS. 


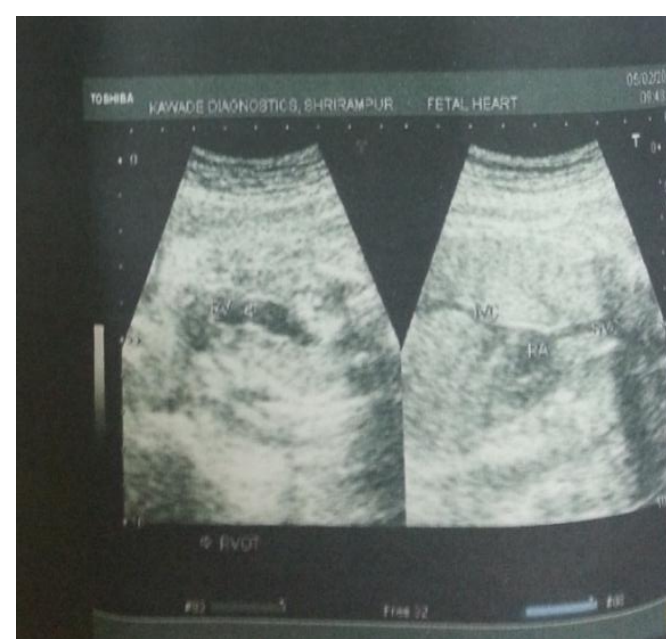

Fig 1: Fetalechograpahy

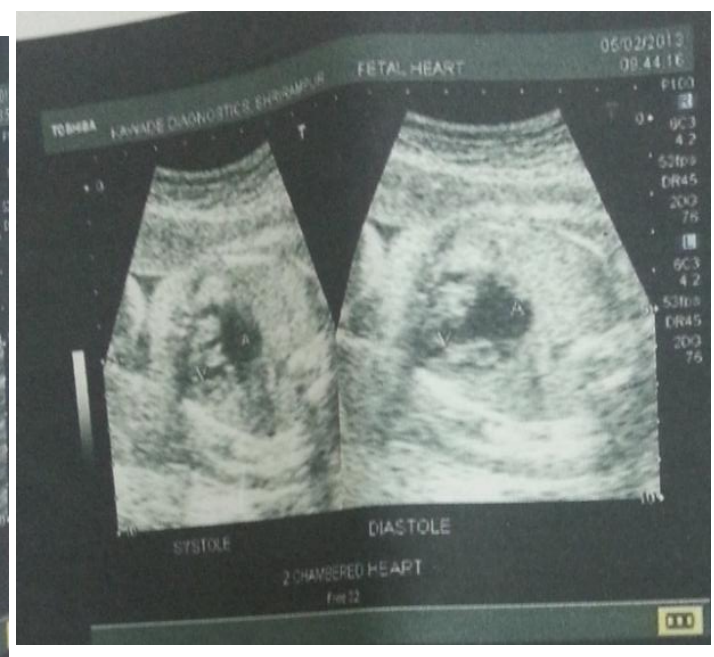

Fig 2: Fetalechograpahy

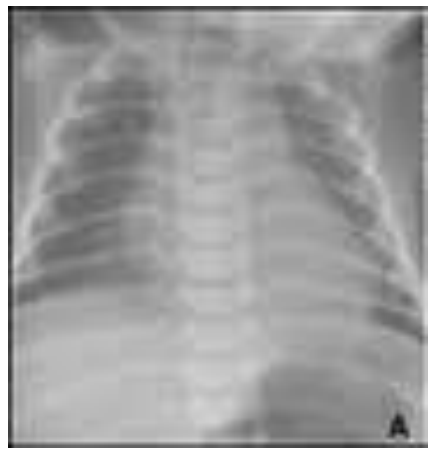

Fig 3: Chest Xray showing cardiomegaly

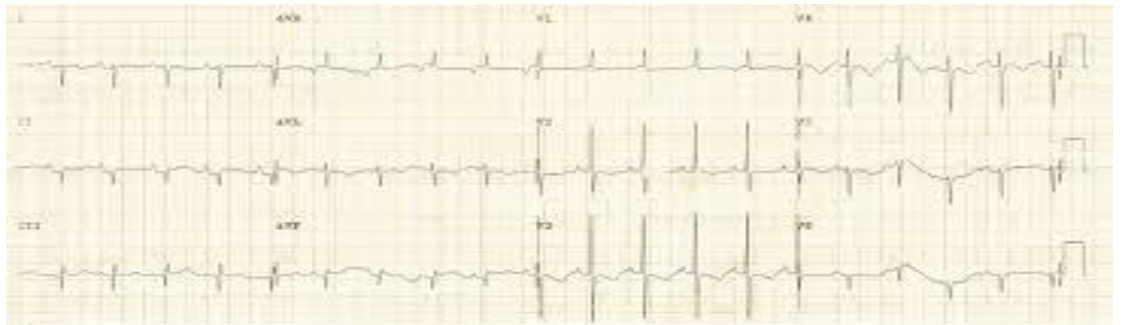

Fig 4: Electrocardiograph showing right axis deviation

\section{Discussion}

Hypoplastic left heart syndrome with an intact atrial septum is a rare finding, reported in only $1 \%$ of pathologic specimens with hypoplasia of the aortic tract complex ${ }^{4}$. With prenatal restriction, or complete premature closure of the foramen ovale (i.e., intact atrial septum), flow is diverted away from the left atrium and left ventricle ${ }^{5}$. Once separation from placental circulation takes place at birth, pulmonary blood flow increases substantially, as does pulmonary venous return to the left atrium ${ }^{6}$. If left ventricular hypoplasia and an intact atrial septum are present, effective egress from the left atrium is impossible, resulting in marked elevation of pulmonary venous pressure ${ }^{7}$.The two surgical procedure most commonly utilized are the Norwood procedure or the Sano procedure, an alternative therapy is cardiac transplantation ${ }^{8}$. The combination of single-ventricle physiology and impediment to pulmonary venous egress can result in postnatal hypoxemia to a degree which may be incompatible with life similar to our case. 


\section{References}

[1]. Allen RH, Benson CB, Haug LW. Pregnancy outcome of fetuses with a diagnosis of hypoplastic left ventricle on prenatal sonography. J Ultrasound Med. 2005;24:1199-1203.

[2]. Nelson Textbook Of Pediatrics, $19^{\text {th }}$ edition, Danial Bernstein, page no 1592-1595

[3]. Better DJ, Apfel HD, Zidere V, Allen LD. Pattern of pulmonary venous blood flow in the hypoplastic left heart syndrome in the fetus. Heart. 1999;81:646-649.

[4]. Rychik J, Rome JJ, Collins MH, DeCampli WM, Spray TL. The hypoplastic left heart syndrome with intact atrial septum: atrial morphology, pulmonary vascular histopathology and outcome. J Am CollCardiol. 1999;34(2):554-60.

[5]. Donofrio MT, Bremer YA, Moskowitz WB. Diagnosis and management of restricted or closed foramen ovale in fetuses with congenital heart disease. Am J Cardiol. 2004;94:1348-1351.

[6]. Rebelo M, Veiga E, Machado AJ, Pinto F, Kaku S. Hypoplastic left heart sindrome with in utero closed foramen ovale: case report. Rev Port Cardiol. 2006 Mar;25(3):331-6.

[7]. Lenz F, Machlitt A, Hartung J, Bollmann R, Chaoui R. Fetal pulmonary venous flow pattern is determined by left atrial pressure: report of two cases of left heart hypoplasia, one with patent and the other with closed interatrial communication. Ultrasound Obstet Gynecol. 2002;19:392-395.

[8]. Norwood WI, Lang P, Hansen DD. Physiologic repair of aortic atresia-hypoplastic left heart syndrome. N Engl J Med. 1983;308:23-6. 